\title{
Non-isolated load sharing direct current system operation with use of the auctioneering diodes
}

\author{
Maciej Kozak ${ }^{*}$ \\ Maritime University of Szczecin, Mechanical Engineering Faculty, 70-500 Szczecin, Poland
}

\begin{abstract}
The paper presents the background and results of numerical simulation and experimental research of a system using auctioneering diodes used to distribute the electrical power between two power converters connected with intermediate circuits in parallel, direct connection. Presented non-isolated power distribution system which utilizes blocking diodes placed in DC branches are used in the selected ship's electrical systems, however, they create problems related to control and handling ground faults. Another issue occurring during the operation of this type of systems is increased heat dissipation while diodes switching. Selected problems related to the operation of experimental system have been identified by means of simulation studies and experiments carried out in a $11 \mathrm{kVA}$ laboratory system and the theoretical basis along with results are provided in the article.
\end{abstract}

\section{Introduction}

DC distributed power systems used onboard of specialized vessels are notable for good efficiency and high power density. There are examples given in the literature [1], of these converters-generators units working in the islanding (or stand-alone) mode but with such structures integrated with a common DC bus in parallel the potential issues which have not been discussed widely can occur. This paper focuses on parallel operation of two different types of alternating current generators connected by means of voltage sources inverters with the objective of control design and presenting interaction issues.

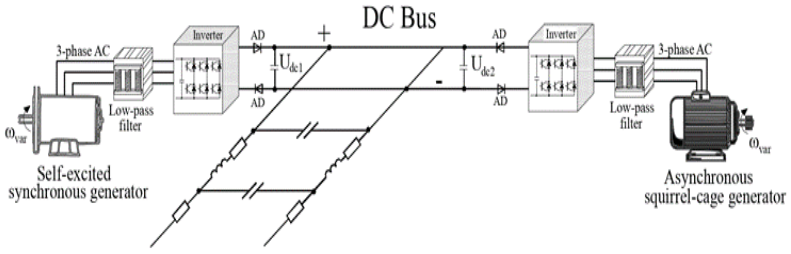

Fig. 1. An example of ship DC grid system with intermediate circuits of inverters connected by auctioneering diodes (AD) in Master/Slave topology.

Because of wide use of parallelized DC supply systems there has been increasing interest in the parallel operation of converters for the reasons of fault tolerance (short circuit or ground fault of common bus) and the low-voltage with high currents demands for power supplies. Many of applicable topologies and proper control schemes have been presented in [2], however, there are only a few papers that are focused on parallel operation of non-isolated $\mathrm{AC} / \mathrm{DC}$ converters and uneven power sharing.

\subsection{System consisting of inverter-generator sets tied with direct current intermediate circuits}

Systems incorporating auctioneering diodes are used to distribute power between renewables and their power converters. The methods of implementation of power sharing are described in [3] but given the autonomous local control of the voltage sources, the focus was on droop methods. The main purpose of the presented system is to distribute power among the generators and inverters as specified by the electrical management system based on the signals analysis obtained from the prime movers. To prevent the flow of circulating currents through conducting transistors of the asynchronous squirrel-cage converter and synchronous self-excited generator inverter connected in parallel, the auctioneering diodes must be implemented into main path of the power circuit. As the connection and power distribution require control of voltage and direct currents charging intermediate circuit capacitors there were machines specific control methods applied. For synchronous motor the FOC was chosen while asynchronous squirrel-cage generator was driven with multiscalar control method.

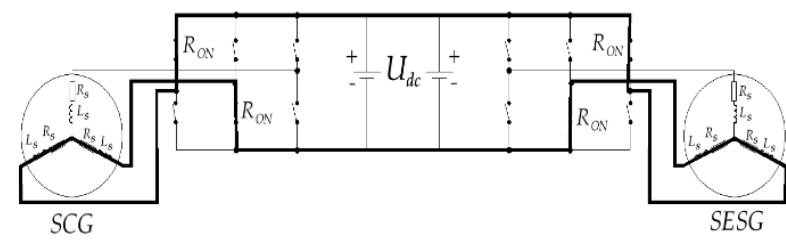

Fig. 2. Path of circulating current flowing through transistors $\left(\mathrm{R}_{\mathrm{ON}}\right)$ of synchronous (SESG) and asynchronous squirrel-cage (SCG) converters [4].

Corresponding author: m.kozak@am.szczecin.pl 


\subsection{Asynchronous generator control methods and properties}

To control an asynchronous generator the special algorithm prepared for the inverter, supporting independent control of the magnetizing and active current was created. The control method chosen for this case was a multiscalar algorithm. The coordinate change proposed in [5] for the rotor flux vector model transforms the induction motor model into a multiscalar model. For purpose of motor or generator control, the transformation of the estimated stator current vector and air-gap flux vector to multiscalar variables can be applied by following relations:

$$
\begin{gathered}
x_{11}=\omega_{r} \\
x_{12}=\Psi_{r \alpha} i_{s \beta}-\Psi_{r \beta} i_{s \alpha} \\
x_{21}=\Psi_{r}^{2} \\
x_{22}=\Psi_{r \alpha} i_{s \alpha}+\Psi_{r \beta} i_{s \beta}
\end{gathered}
$$

where $\mathrm{x}_{11}$ is the rotor speed, $\mathrm{x}_{12}$ is the variable proportional to electromagnetic torque, $\mathrm{x}_{21}$ depends on rotor flux value, and $\mathrm{x}_{22}$ represents the so so-called magnetized variable. As it can be seen the asynchronous generator torque is independent of the rotor flux position and stator current in any reference plane so the generator torque depends on the mutual position of the vector flux and stator currents.

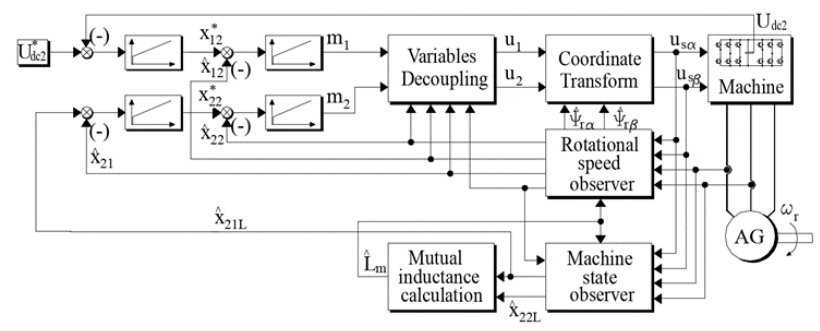

Fig. 3. The scheme of the nonlinear multiscalar control structure of asynchronous generator (AG).

When a generator operates within a range up to nominal speeds, errors arising from numerical integration of stator currents are small and can be omitted, but in the case of field weakening region operation, the system may get unstable. Because of this issue investigated control algorithm was supplemented by a disturbances observer which reduced steady state errors in high speed region operation.

\section{Experimental results of uneven load sharing}

To verify the developed power sharing method, the proposed system was subjected to laboratory tests. To drive the generators, inverter supplied induction machines were utilized. Such solution made it possible to observe the power flow and precisely record the input parameters, such as torque and angular speed.

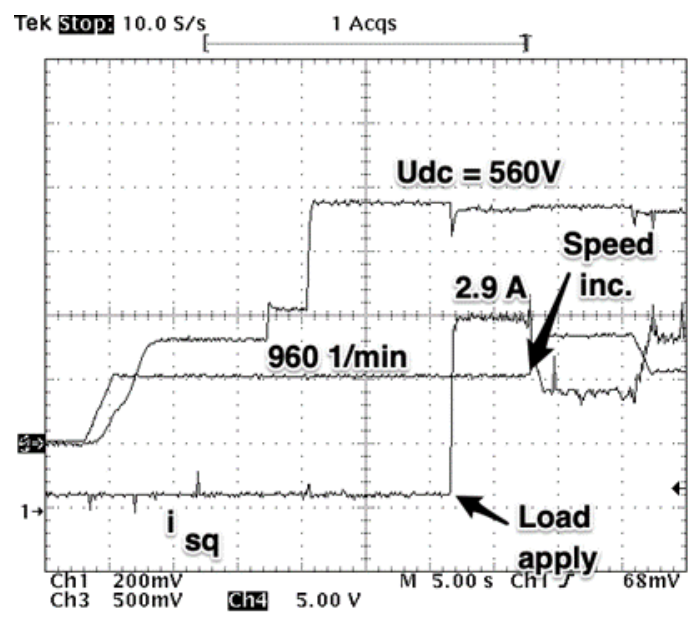

Fig. 4. Waveforms of DC voltage, active current, with load apply application and load shedding during rotational speed changes.

\section{Conclusions and final thoughts}

Based on the results of the experimental studies system consisting of two alternators can operate in parallel connection of their intermediate circuits for a long period of time. The amount of power dissipated in auctioneering diodes is higher in parallel operation in comparison to island mode therefore this type of system requires more efficient cooling.

\section{References}

1. R. Balog; P.T. Krein. Bus Selection in Multibus DC Microgrids. IEEE Transactions on Power Electronics 2011 Volume 26 (3), pp. 860-867, 10.1109/TPEL.2010.2094208

2. E. Tironi; M. Corti; G. Ubezio. Zonal electrical distribution systems in large ships: Topology and control. AEIT International Annual Conference 2015, IEEE Xplore. 10.1109/AEIT.2015.7415252.

3. R. Balog. Autonomous local control in distributed DC power systems. Ph.D. Thesis, Department of Electrical and Computer Engineering, University of Illinois at UrbanaChampaign, 2006

4. M. Kozak. Alternating Current Electric Generator Machine Inverters in a Parallel Power Sharing Connection, IEEE Access, Volume: 7, Pages:32154-32165, DOI 10.1109/ACCESS.2019.2902647.

5. Z. Krzemiński. Nonlinear control of induction motor. Proceedings of the 10th IFAC World Congress, Munich 1987. 